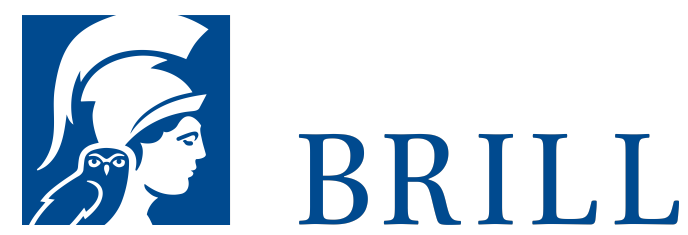

\title{
Ein neues Menschenbild?
}

Der Anspruch der Neurowissenschaften auf Revision unseres Selbstverständnisses

Author: Birgit Beck

Vor einigen Jahren prognostizierten renommierte Hirnforscher im sog. 'Manifest' eine einschneidende Veränderung unseres Menschenbildes. Diese Vorhersage hat großes Aufsehen erregt und zu einer vermehrten Bezugnahme und Berufung auf Menschenbilder in der öffentlichen Debatte geführt, in welcher auch der Befürchtung einer neurobiologischen Kränkung des menschlichen Selbstverständnisses Ausdruck verliehen wurde. Dennoch ist bislang weder klar, was unter unserem Menschenbild genau zu verstehen ist, noch wie ein revidiertes Selbstverständnis aussehen könnte. Dieses Buch rekonstruiert das traditionelle Menschenbild und unterzieht radikale und aufsehenerregende Thesen, die in Reaktion auf neurowissenschaftliche Erkenntnisse aufgestellt wurden, einer kritischen Analyse. Dies betrifft insbesondere zentrale Fragen nach dem menschlichen Geist, Freiheit und Verantwortung, der menschlichen Natur und Personalität. Das Ziel der Untersuchung besteht darin, einem unreflektierten und vorschnellen Fatalismus entgegenzuwirken, den Kränkungsverdacht zu entkräften sowie erwartbare positive Konsequenzen eines neurobiologisch informierten naturalistischen Menschenbildes aufzuzeigen.

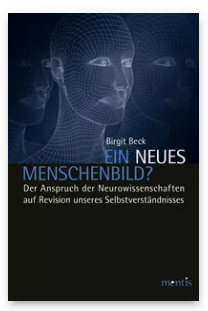

Pages: 315

Seiten

Language:

German

Subjects:

General,

Philosophy

Publisher: Brill | mentis

E-Book (PDF)

Released online:

o1 Jun 2013

ISBN: 978-3-

95743-948-2

List price

Paperback

Publication date: o1 Jun 2013

ISBN: 978-389785-828-2 List price 
For more information see brill.com

Order information: Order online at brill.com +44330 333 0049 | customerservices@brill.com Submission information: brill.com/authors

Titles published by Brill | Fink, Brill | mentis or Brill | Schöningh: +49(o)715413279216| brill@brocom.de 